International Journal of Applied Economics, Finance and Accounting

ISSN 2577-767X

Vol. 7, No. 1, pp. 1-9.

2020

DOI: $10.33094 / 8.2017 .2020 .71 .1 .9$

(C) 2020 by the authors; licensee Online Academic Press, USA

\title{
Effect of Glass Ceiling on the Earning Factor: A Case of UK
}

\author{
Liqun Qian ${ }^{1 *}$ \\ John Watson \\ Tony Bell ${ }^{s}$
}

${ }_{1,2}$ Western Carolina University, USA.
${ }^{2}$ Email: liqun-qian@wcu.edu
${ }^{s}$ Rutgers University, USA.
Licensed:
This work is licensed under a Creative
Commons Attribution 4.0 License.
Keywords:
Glass ceiling
Earningfactor.
JEL Classification
D33; F41.
Accepted: 10 June 2020
Published: 25 June 2020
(* Corresponding Author)

\begin{abstract}
The aim of this research has been to examine the impact of glass ceiling on the earning factor. The case of organisations that are operating in UK have considered in this study. The use of quantitative research design has been made in this study along with primary data collection through survey questionnaire. The data was analysed through Structural Equation Modelling (SEM) model on SmartPLS. It has been found that beliefs, culture, policy, self-perception and willingness to work have a significant and positive effect on earning factor, whereas ability to work, work-life balance and stereotypes were found to have insignificant effect on earning factor. The entire study was based on UK, thus the scope of this research has been more broad and generalised, as all those organisations that are operating in UK have been assessed. However, future researchers can narrow down the research scope to any particular industry or organisation to provide more concise and conclusive results.
\end{abstract}

Funding: This study received no specific financial support.

Competing Interests: The authors declare that they have no competing interests.

\section{Introduction}

The participation of women into the workplace has increased significantly based on the fact that movement of equality has emerged from developed countries to developing country; whereas rising awareness, lifestyle changes and shifts it demographics have all contributed to higher participation of women in an economy. However, gender-pay gap still remains a phenomenon around the world including the glass ceiling within the organisations (Bishu \& Alkadry, 2017). In this regard, Xiu and Gunderson (2014) has defined that it commonly believed that women have lesser career advancement opportunities than their counterparts' men within the same workplace. This is a form of glass ceiling that refers to the invisible barriers being imposed on the advancement of women careers. Meanwhile, glass ceiling takes place when the advancement of women in career is halted based on the discrimination in form of sexism and racism (Fortin, Bell, \& Böhm, 2017). Meanwhile, the limitations and blocks towards advancement are unwritten and unofficial policy hence it remains unseen, transparent and undetected but still active in place. This is also major reason disparity could be found in male and female representation in various developed and developed countries around the world. Hence, due to low disparity in sectors, there are very insignificant number of women on top positions and have decision making position (Blau \& Kahn, 2017).

Meanwhile, in opposition to glass ceiling within UK, Cox (2019) argues that women were granted voting rights 100 years back, and 50 years after Equal Pay act the gender pay gap stills remains within the organisations based on the discrimination against the women. In this regards, The Fawcett Society's study reveals that around one third of the employees are not aware of their rights that being paid unequally based on gender is illegal as per the Equality Act pay. This discrimination is shielded by culture of pay secrecy and thrives the pay inequality within the system despite it is employees' legal right to discuss their pay with their colleagues. Furthermore, there are four times high men on highest-paid jobs in UK than women; as of 201516 there were 17000 men those earned around 1 million and compare this only 2000 women earned 1 million during the same period. This fact can be further strengthened by another statistic that the median annual income of the men is 25700 and median annual income of the 20300; this suggests that women have been earning less than their male counterparts, triggering an alarming situation that since numbers do not account for the part-time workers and low-paid workers (Savage, 2018).

The prevalence of the gender disparity and unequal pays are entirely opposed to what has been proposed by the Law; and this has also remained a major gender bias in career advancement for the women in large 
organisations (Sharma \& Sehrawat, 2014). Therefore, the stereotypes against the women are contributing factors that develop glass ceiling within the organisation; as the women have been seen as weak, highly emotional and unaggressive to occupy the high-level position since people may not be controlled by a woman. Similarly, this is study is specifically aimed to identify those factors that lead to the glass ceiling within organisational cultures and overall affecting the level of income or earning factor for the women (Nilufer Azeez \& Priyadarshini, 2018). Hence, this study holds significant value for the policy makers and decision makers to formulate strategies in accordance with the factors leading glass ceiling and reducing the pay gaps through appropriate measures to ensure neither of the party is affected. Therefore, in order to approach this boarder aim, following sub-objectives has been constructed as follows

\section{Aim and Objectives}

The aim of this study will be to examine the impact of glass ceiling on earning factor. Following are the set of objectives that will be followed for this study:

- To understand the theoretical concept of glass ceiling and earning factor from literature.

- To identify the factors of glass ceiling that affects earning factor.

- To identify the relationship between glass ceiling and earning factor.

- To recommend how gender pay gap issues can be reduced for career development of both genders.

\section{Research Question}

What are the factors of glass ceiling that influence earning factor?

\section{Literature Review}

4.1. Conceptualization of Glass Ceiling and Earning Factor

Sharma and Sehrawat (2014) defines glass ceiling as invisible barriers to restrict women heading towards senior level management position in the organisations. It is not a single wall or one ceiling but rather multiple and varying forms of pervasive gender biases takes places covertly or overtly (Nilufer Azeez \& Priyadarshini, 2018). However, the literature have bears positive and negative attitudes towards the glass ceiling and many authors present their own arguments against and favour of the glass ceiling; for instances Rai and Srivastava (2010) have argued that there is nothing like glass ceiling in corporations and women have lessor chances to be promoted to higher posts due to the fact that they could have a tendency to leave the job in middle of the hour, almost have less working hours, less motivated to work late hours and also prefer to remain within low risk jobs that means being a soft corner.

In contrast to this, Ryan and Haslam (2011) have argued that firms at very lower level of performance require a leader should show feminine attributes of being sympatric, relationship developing, service oriented and also caring others in hard times. Therefore, the glass ceiling concept is a gender-based phenomenon that prevails within the organisations but have certain other influencing factors including the stereotypes against the capabilities and skills of the women. Similarly, the earning factor refers to the level of wages and annual income to the men and women; where it has also been stated by Blau and Kahn (2017) that the presence of the gap between the men and women reveals the glass ceiling within the organisations. The core reason behind the lower pay is due to culture of pay secrecy that restricts the colleagues to talk about the pay. In addition to, Bertrand, Black, Jensen, and Lleras-Muney (2019) found that 8 out of 10 companies in UK have been paying men more than women. Similarly, more than quarter of the women have never asked to raise the pay based on the that they fear or losing job or being replaced by a men employee (Oppenheim, 2019). Meanwhile, the study also reveals that 4 out of 5 women do not negotiate the pay in an interview which also shows that women have undermined their capabilities and chances of being paid higher due to the fear and stereotypes against them (Oppenheim, 2019a).

\subsection{Factors Leading to Glass Ceiling}

There are three types of factors that are influencing the glass ceiling within the organisation and these includes as follows.

\subsubsection{Personal Factors}

Under the node of personal factors include the ability of the employee to work and willingness to execute the given job because these two factors are personal attributes of the employee that could create a glass ceiling against the women. In addition to, self-perception and work-life balance are two other contributing factors that have been cited to be influencing the glass ceiling within the organisation and leading to higher pay gaps (Nilufer Azeez \& Priyadarshini, 2018). It is because, the barriers before the advancement of women may be put in place when position requires higher working hours and is a job with always pressure; hence in this condition the women may be considered softer for that position. In addition to this, it is also believed that to be more focused on the family rather than work this attributed could have a devasting consequences for the position to which a woman may be chairing thus glass ceiling could rise in this sense so as the pay gap. 


\subsubsection{Organizational Factors}

Under the node of organisational factors include the policies and culture of organisation also the perception held by management against the career advancement of the women. Since, the management is reluctant to invest into the women employees as it is common belief that women may quiet the job; hence due to this reason there are few opportunities for the women employees although the women employees may have sufficient skills and high coordinating ability (Nilufer Azeez \& Priyadarshini, 2018). However, due predeveloped stereotypes create gender-based biases within the organisation and ultimately creates glass ceiling for the women in form of invisible wall.

\subsubsection{Societal Factors}

Under the node of societal factors there includes the beliefs and stereotypes within the society regarding the women and these societal factors often influence employment development within an organisation. Similarly, it is commonly believed that women are weak and highly emotional and that she has to be homemaker rather than a top management employee at decision making position (Nilufer Azeez \& Priyadarshini, 2018). Due to these stereotypes, it is more likely that organisations prefer to have higher positions to men with higher salaries as compared to women.

\section{Impact of Glass Ceiling on Earning Factor}

A study conducted by Nilufer Azeez and Priyadarshini (2018) in IT sector of India, tried to identify the factors that have been contributing to the glass ceiling within the organisations ultimately cause pay gap between the men and women. The author identified three categories of factors that have been affecting the glass ceiling and these factors include personal factors, organisational factors and societal factors. Furthermore, the core aim of the study was to identify critical factors that creates glass ceiling against the women at workplace and becomes an obstacle for the career advancement opportunity. Meanwhile, for the purpose of study, survey was conducted from 57 female employees from IT companies operating in India. The findings of the study have suggested that social factors are more responsible for the development of glass ceiling within the organisations since it also affects the women' perception about themselves and perception of the management against the women regarding promotion to higher position.

Furthermore, another study conducted by Afza and Newaz (2008) attempted to examine the presence of glass ceiling in various manufacturing and services industries; and specifically focused on the identifying the factors that have been creating glass ceiling for the women at workplace and restrict them to be promoted to higher levels. The study identified five factors that include organisational policy, sexual harassment, work-life conflict, perception of management and environment of work. The findings of the study suggested that work environment and perception of management are significant factors that have been creating the glass ceiling within the organisation; on the other hand, organisational policy and work-life conflict are second significant factors leading to glass ceiling within the organisation. In contrast, the study also found that support of family, positive attitude towards organisation and career focused positively influences the advancement of the women within organisation.

In addition to the glass ceiling, women are also at higher risk of being hired at lower pay as compared to the men. In this regard, a study conducted by Lips (2013) tried to understand the factors influencing the gender pay and author has argued that there are certain factors that have been contributing to gender pay gap for instances the part-time working, unionization, gender segregation and parenthood are certain factors that contribute to pay gap between the male and female. However, Similarly, Bargain and Melly (2008) argues that it is not matter to compare the gap but the subject is to determine how pay gap interacts with the influences. Therefore, it is evident that pay gap within the organisation prevails but it may not be due to the glass ceiling rather certain other factors could have influenced the pay gap. Thus, irrespective of exploring the differences, it is critical to explain how pay gap takes place and identify those influences.

\section{Methodology}

In order to achieve the aim of the study, the researcher will be using deductive approach alongside positivist philosophy. As hypothesis testing of both variables is important therefore, quantitative method of research design and primary data will be collected. The primary data will be collected through structured survey questionnaire. The questionnaire will be designed on 5-point Likert scale. The sample size selected for this study will be 250. The purpose of taking a large sample size was to ensure that the data collected is reliable and more authentic. Also, the data analysis technique used in this study will be PSL so that relationship can be tested between the variables.

\section{Findings and Analysis}

In the previous section of this study, the brief discussions on research methods that have been followed in this study were presented. This section is related to conduct the analysis on research findings through different statistical tests. In this regard, the use of Structural Equation Modelling (SEM) technique has been made to analyse the collected data. As per the study of Lowry and Gaskin (2014) SEM is probably the most 
useful way to analyse or measure structural associations between different variables of the study. In accordance with the same study, SEM techniques are considered to be more useful for analysing complex models with latent variables. Therefore, through SEM method, researcher has conducted confirmatory factor analysis and path analysis in this study.

\subsection{Confirmatory Factor Analysis}

Confirmatory factor analysis is regarded as one of the major component of SEM technique, which helps in analysing quantitative data. According to Marsh, Guo, Dicke, Parker, and Craven (2020) the main purpose of using confirmatory factor analysis is to analyse that how well all the measured variables are representing the number of constructs. In other words, it is mainly used to confirm that data firs well with the hypothesized measurement model. In accordance with the study of Taber (2018) all the constructs can viewed as valid, if the values of factor loadings, composite reliability and Cronbach's Alpha are at-least 0.6 or above 0.6. Thus, researcher in this study has also opted for following the same criteria by setting 0.6 as the benchmark for all the mentioned measures. Moreover, the convergent validity was also investigated through Average Variance Extracted (AVE). According to Chung, Ko, Joung, and Kim (2018) in order to prove the convergent validity of all the constructs, the value of AVE needs to be 0.5 or more than 0.5 . The Table 1 presents the results pertaining to convergent validity and reliability of all the variables that have incorporated in this study.

Table-1. Confirmatory factor analysis.

\begin{tabular}{|c|c|c|c|c|}
\hline & Factors Loadings & Cronbach's Alpha & $\begin{array}{l}\text { Composite } \\
\text { Reliability }\end{array}$ & $\begin{array}{l}\text { Average Variance } \\
\text { Extracted (AVE) }\end{array}$ \\
\hline & & 0.696 & 0.863 & 0.760 \\
\hline AW1 & 0.815 & & & \\
\hline $\mathrm{AW} 2$ & 0.925 & & & \\
\hline$\overline{\text { BEL1 }}$ & 0.853 & 0.893 & 0.924 & 0.754 \\
\hline BEL2 & 0.856 & & & \\
\hline BEL3 & 0.880 & & & \\
\hline BEL4 & 0.883 & & & \\
\hline CUL1 & 0.889 & 0.743 & 0.886 & 0.796 \\
\hline CUL2 & 0.895 & & & \\
\hline EF 1 & 0.800 & 0.878 & 0.916 & 0.733 \\
\hline $\mathrm{EF} 2$ & 0.871 & & & \\
\hline EF3 & 0.892 & & & \\
\hline $\mathrm{EF} 4$ & 0.859 & & & \\
\hline POL1 & 0.933 & 0.772 & 0.828 & 0.621 \\
\hline POL2 & 0.675 & & & \\
\hline POL3 & 0.738 & & & \\
\hline $\mathrm{SP} 1$ & 0.943 & 0.861 & 0.935 & 0.877 \\
\hline $\mathrm{SP} 2$ & 0.930 & & & \\
\hline $\mathrm{ST} 1$ & 0.749 & 0.716 & 0.855 & 0.750 \\
\hline $\mathrm{ST} 2$ & 0.968 & & & \\
\hline WLB1 & 0.900 & 0.839 & 0.924 & 0.858 \\
\hline WLB2 & 0.952 & & & \\
\hline WW1 & 0.939 & 0.718 & 0.870 & 0.770 \\
\hline WW2 & 0.811 & & & \\
\hline
\end{tabular}




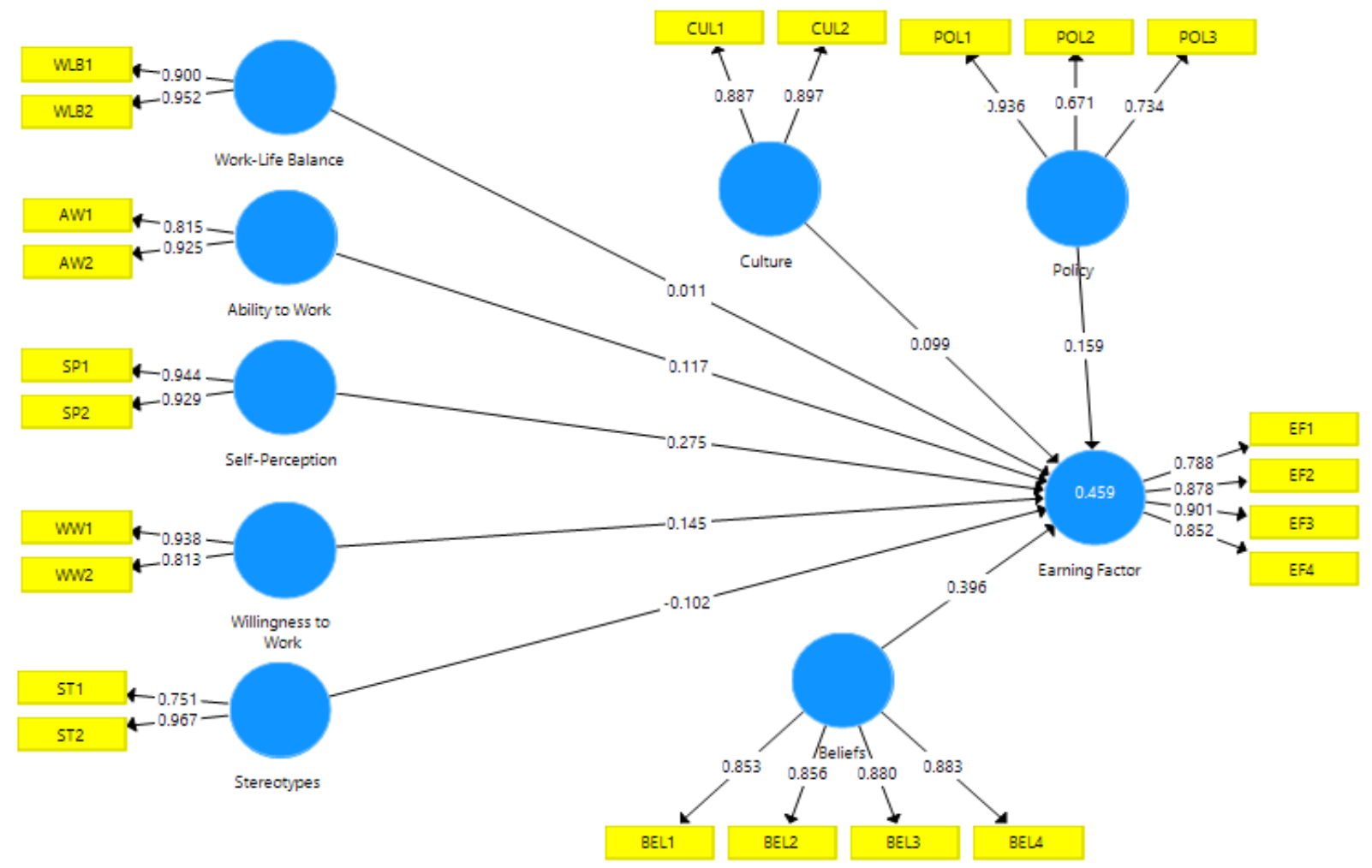

Figure-1. Measurement model of the research.

All the Cronbach's Alpha values of each variable that are outlined in Table 1 are above the set benchmark, which was 0.6. This confirms that all the test items that are added in this research are reliable and consistent. Similarly, all the values of factor loadings that are highlighted in Table 1 are also greater than 0.6, which is enough to ensure the reliability of all the constructs, thus there was no need for drooping any constructs from the study. Similarly, the aforementioned Figure 1 also highlights the values of factor loading, which also confirms the reliability of all the constructs. Apart from that, all the values of AVE that are presented in Table 1 is explaining the level of variance existed in all the variables, which is demonstrated by latent constructs. All the values of AVE highlighted in Table 1 are found to be greater than 0.5 , which is enough to prove the convergent validity of all the constructs.

\subsection{Discriminant Validity}

In order to measure the influence of glass ceiling on earning factors, researcher has selected different factors of glass ceiling, which falls under personal, organisational, and societal factors. Hence, it is important to perform the test of discriminant validity to determine that whether all the constructs that needs to be unmatched are actually distinct or not.

\begin{tabular}{|c|c|c|c|c|c|c|c|c|c|}
\hline $\begin{array}{c}\text { Heterotrait- } \\
\text { Monotrait } \\
\text { Ratio } \\
\text { (HTMT) }\end{array}$ & $\begin{array}{l}\text { Ability } \\
\text { to work }\end{array}$ & Beliefs & Culture & $\begin{array}{l}\text { Earning } \\
\text { Factor }\end{array}$ & Policy & $\begin{array}{l}\text { Self- } \\
\text { Perce } \\
\text { ption }\end{array}$ & Stereotypes & $\begin{array}{l}\text { Willing } \\
\text { ness to } \\
\text { Work }\end{array}$ & $\begin{array}{l}\text { Work- } \\
\text { Life } \\
\text { Balance }\end{array}$ \\
\hline Beliefs & 0.267 & & & & & & & & \\
\hline Culture & 0.522 & 0.449 & & & & & & & \\
\hline $\begin{array}{l}\text { Earning } \\
\text { Factor }\end{array}$ & 0.416 & 0.584 & 0.300 & & & & & & \\
\hline Policy & 0.333 & 0.197 & 0.401 & 0.337 & & & & & \\
\hline $\begin{array}{c}\text { Self- } \\
\text { Perception }\end{array}$ & 0.539 & 0.413 & 0.472 & 0.585 & 0.447 & & & & \\
\hline Stereotypes & 0.709 & 0.320 & 0.608 & 0.336 & 0.361 & 0.747 & & & \\
\hline $\begin{array}{c}\text { Willingness } \\
\text { to Work }\end{array}$ & 0.510 & 0.350 & 0.376 & 0.484 & 0.216 & 0.619 & 0.563 & & \\
\hline $\begin{array}{c}\text { Work-Life } \\
\text { Balance }\end{array}$ & 0.653 & 0.302 & 0.596 & 0.341 & 0.227 & 0.499 & 0.623 & 0.590 & \\
\hline
\end{tabular}


The discriminant validity was conducted through Heterotrait-Monotrait ratio, the results of which are presented in Table 2. According to Ab Hamid, Sami, and Sidek (2017) for ensuring that all the variables that are incorporated in a model are not linked and dissimilar with each other, the Heterotrait-Monotrait ratio value should needs to be below 0.85 . In this regard, the values of each variable that are outlined in Table 2 are below 0.85 , which confirms the discriminant validity of all the variables.

\subsection{Model Specification}

According to Yehia, Saleh, and Ahmed (2016) the value of R-square shows the proportion of variances on dependent variable that is explained by all the independent variables incorporated in a model; whereas adjusted r-square is considered as more improved version of r-square.

\begin{tabular}{c|c|c}
\multicolumn{3}{c}{ Table-3. Model specification. } \\
\hline & R Square & R Square Adjusted \\
\hline Earning Factor & 0.459 & 0.447 \\
\hline
\end{tabular}

The $\mathrm{R}$ square value of earning factor that is highlighted in Table 3 is 0.459 . This means that $45.9 \%$ of the changes in earning factor are explained by all the independent variables that are added in this research.

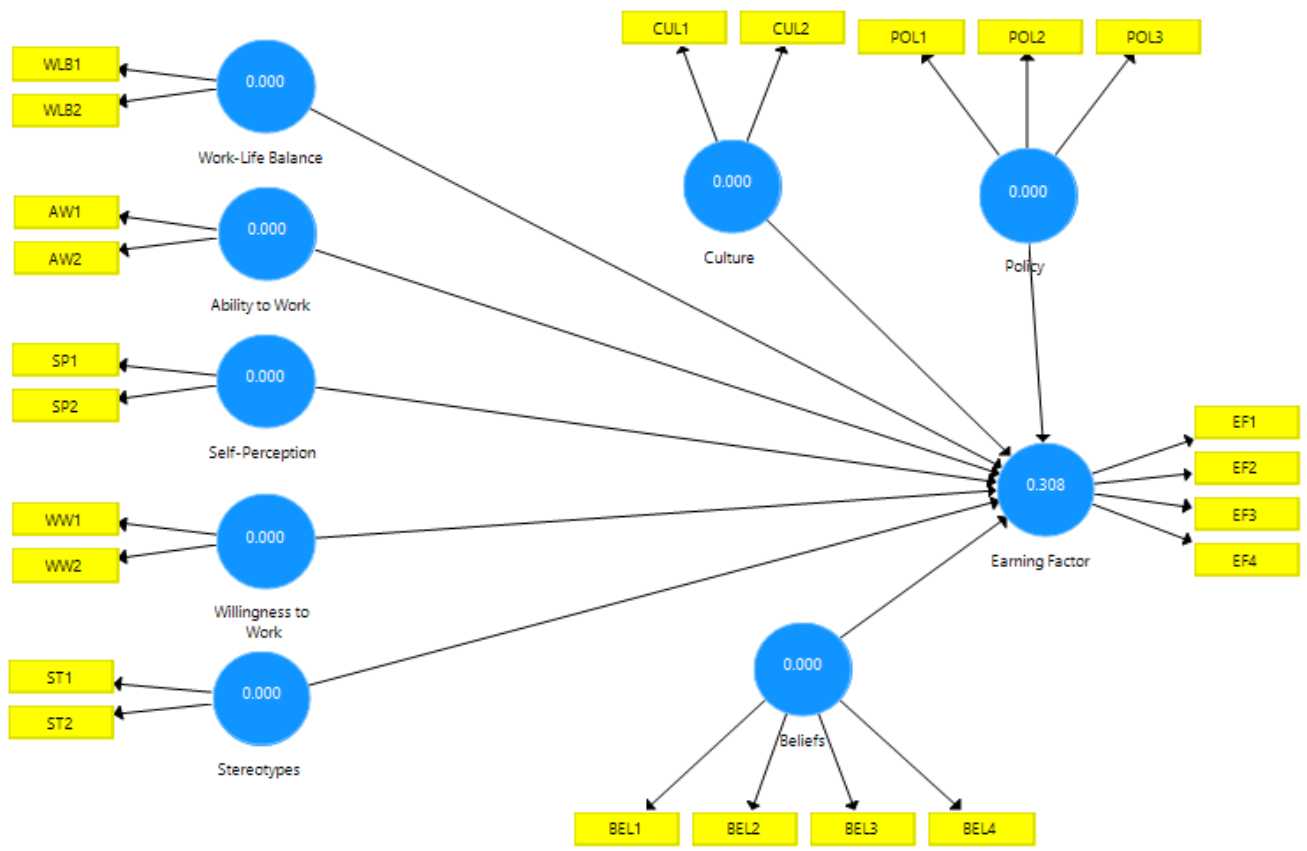

Figure-2. Blindfolding of the model.

\subsection{Path Assessment}

One of the main objectives of this research was to analyse the impact of glass ceiling on the earning factor. To achieve that objective, researcher has identified different factors of glass ceiling through which the association between glass ceiling and earning factor was examined. Some of the major factors leading to glass ceiling was ability to work, beliefs, culture, policy, stereotypes, self-perception, willingness to work, and worklife balance. In order to analyse the impact of all these factors on earning factor, researcher has conducted path assessment test. As per the study of Shmueli et al. (2019) path assessment test is one of the most effective way to measure the relationships between different variables.

\begin{tabular}{l|c|c|c}
\hline \multicolumn{4}{c}{ Table-4. Path coefficient. } \\
\hline Ability to Work -> Earning Factor & Original Sample & T Statistics & P Values \\
\hline Beliefs -> Earning Factor & 0.117 & 1.911 & 0.056 \\
\hline Culture -> Earning Factor & 0.396 & 9.792 & 0.000 \\
\hline Policy -> Earning Factor & 0.099 & 2.073 & 0.038 \\
\hline Self-Perception -> Earning Factor & 0.159 & 3.188 & 0.001 \\
\hline Stereotypes -> Earning Factor & 0.275 & 4.353 & 0.000 \\
\hline Willingness to Work -> Earning Factor & -0.102 & 1.724 & 0.085 \\
\hline Work-Life Balance -> Earning Factor & 0.145 & 2.612 & 0.009 \\
\hline
\end{tabular}




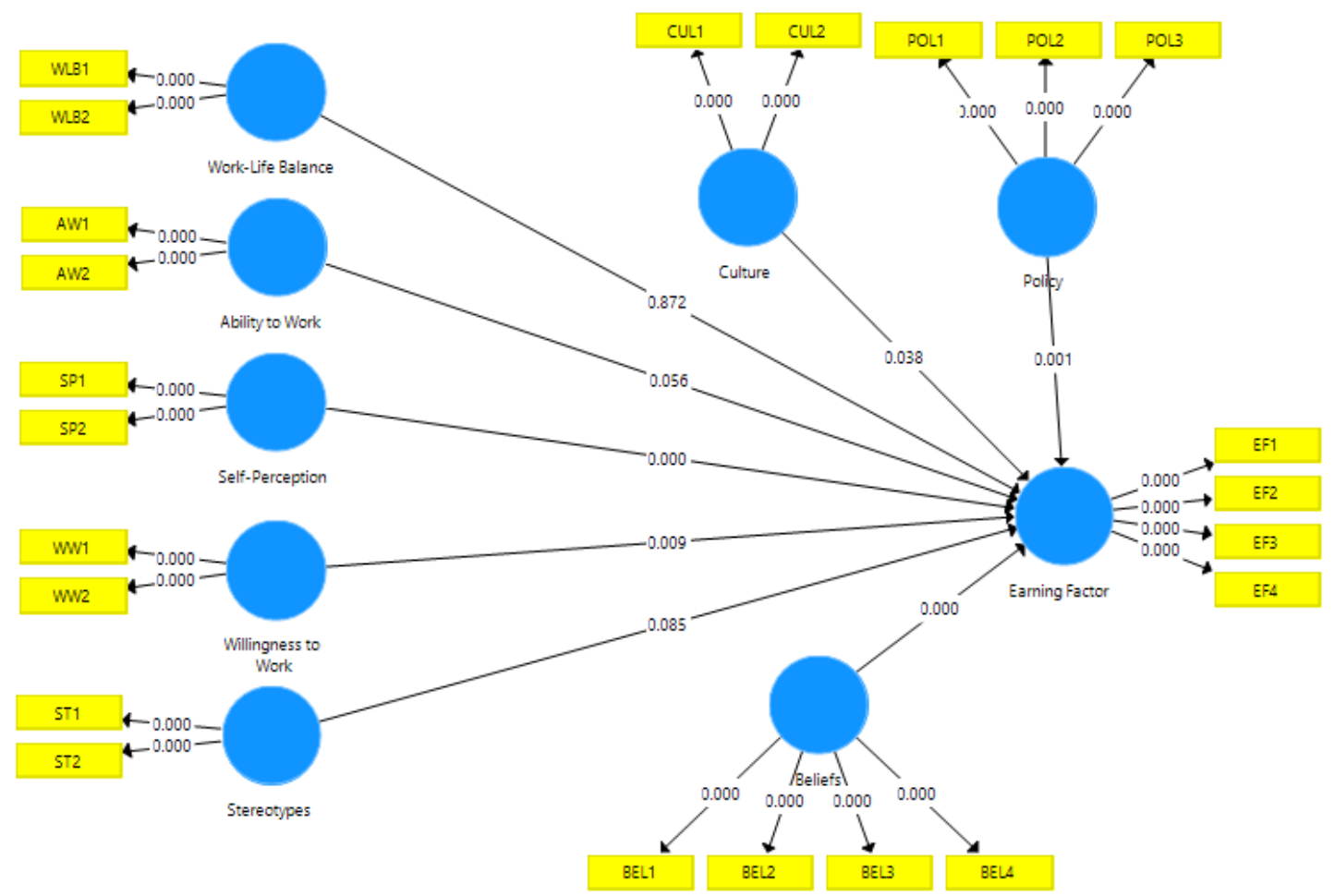

Figure-3. Bootstrapping with p-values.

In accordance with the findings of path assessment that are presented in Table 4, and also highlighted in Figure 3, the independent variables including beliefs, culture, policy, self-perception, and willingness to work are to found to have a significant impact on earning factor, as the p-value of all these variables are fall under the 0.05. In contrast, the independent variables including ability to work, stereotypes, and work-life balance are found to have an insignificant impact on earning factor, as the values of all these variables have exceed the limit of 0.05 .

\section{Discussion}

The major aim of this research has been to investigate the impact of glass ceiling on earning factor in the context of UK. Apart from that, this study was also concerned with identifying the key factors of glass ceiling that can influence earning factor. For that purpose, the review of previous literature has also been made along with the collection primary quantitative data. The factors of glass ceiling that have been identified in this study are found to be fall in three categories, which includes personal factors, social factors, and organisational factors. In this regard, the overall factors that are highlighted and use for measuring the variable of glass ceiling includes ability to work, culture, beliefs, self-perception, policy, stereotypes, work-life balance, and willingness to work. The results of survey questionnaires reveal the significant and positive impact of culture, beliefs, policy, self-perception, and willingness to work on earning factor. These results are also found to be validated from different previous studies, in which same variables were identified that makes the significant influence on earning factors. As mentioned in the study of Afza and Newaz (2008) the willingness to work and self-perception plays a pivotal role in the development of glass ceiling, and in influencing the earning factor. On the other hand, the study carried out by Bargain and Melly (2008) determines policy, beliefs and culture as the important component of glass ceiling that can positively influence the earning factor.

The findings of this research also outline three factors of glass ceiling that are found to have an insignificant effect on earning factor. These factors include ability to work, stereotypes and work-life balance. However, this result is found to be contradicting with previous studies, in which personal factors are identified as the major components of glass ceiling that can make the positive influence on earning factors (Nilufer Azeez \& Priyadarshini, 2018). Overall, the findings of this research confirm the significant influence of glass ceiling on earning factors in the context of UK.

\section{Conclusion}

The overall analysis and discussion of research outcomes portrays the huge role of glass ceiling on influencing the level of income and wages for both men and women. The key purpose of the study was to examine the impact of glass ceiling on earning factor. In this regard, different research objectives have been formed to break down the main research aim into different steps, so that each aspect of the research topic can be effectively catered. With respect to methodology, researcher has followed quantitative research design, and 
incorporated primary data collection method. In this manner, researcher has conducted the survey questionnaire from relevant people, so that most authentic and relevant information can be gathered. Apart from that, in data analysis researcher has conducted Structural Equation Modelling (SEM) through PLS software.

The first main objective of this study was to gain the theoretical understanding of the concept of glass ceiling and earning factor. The concept of glass ceiling has been viewed as an invisible barrier that impose the restrictions on women in a way of achieving higher managerial position within the organisation (Sharma \& Sehrawat, 2014). On the other hand, the concept of earning factor is mainly referred to the level of annual income and wages to the women and men (Blau \& Kahn, 2017). Apart from that, the second objective of this research was to identify the factors of glass ceiling. Hence, the factors of glass ceiling that have been found in this study include ability to work, culture, self-perception, beliefs, policy, stereotypes, work-life balance, and willingness to work. Lastly, the impact of all these factors has been assessed on earning factor. In this context, the variable of culture, beliefs, self-perception, policy, and willingness to work are found to have a significant effect on earning factor, whereas the findings of this research reveals the insignificant effect of ability to work, work-life balance and stereotypes on earning factor.

\section{Recommendations}

The last objective of this research was to propose some sound recommendations regarding how the pay gap issues can be addressed for the career development of both genders. Therefore, based on the overall findings of this research, following recommendations are proposed:

- For a company to promote salary equality in the organisation requires high level of commitment, analysis and strategies to effectively manage employees. Firstly, it has been recommended for the company to must conduct the analysis of gender pay gap by collecting the data of employee's level of salaries on the basis of tenure, gender, education, department etc. In this manner, company will be able to find pay gap issues can eventually make suitable strategies to address these issues.

- Companies that are operating in UK are also advised to show high commitment towards equal pay pledge. In this regard, companies are required to set the clear set of rules and competencies related requirement that both genders needs to display in order to attain higher salary and to achieve senior level position within the organisation.

- The distribution of bonuses, promotions and performance reviews can be highly influenced by unconscious biasness related to favouritism, male based definition of success and behavioural trait. Therefore, it is important for companies to provide proper training to their managers regarding the equalise performance reviews, so that both men and women are being fairly treated and evaluated.

\section{Limitations and Future Research}

One of the major limitations of this research has been associated with its limited scope, as this study was entirely based on UK. Thus, the overall analysis and findings that are presented in this research cannot be applied to any other context or country. Taking this limitation into consideration, future researchers can consider broadening the scope of this study by carrying out this research more wider context by covering different countries. Moreover, the scope of this research can also be narrowed down to any specific organisation, so that more accurate and precise information can be gathered. On the other hand, this study was entirely based on quantitative research design, which to some extent has affected the quality of overall findings. Therefore, in future the same study can be carried out with mixed research design, in which researcher will gather and analyse both quantitative and qualitative data. This will allow the researcher to provide more conclusive findings, and also ensures the validation of research outcomes through comparing the results of both quantitative and qualitative data.

\section{References}

Ab Hamid, M., Sami, W., \& Sidek, M. (2017). Discriminant validity assessment: Use of Fornell \& Larcker criterion versus HTMT criterion. In Journal of Physics: Conference Series (Vol. 890, No. 1, p. 012163), IOP Publishing.

Afza, S. R., \& Newaz, M. K. (2008). Factors determining the presence of glass ceiling and influencing women career advancement in Bangladesh.

Bargain, O., \& Melly, B. (2008). Public sector pay gap in France: new evidence using panel data. Available at SSRN 1136232.

Bertrand, M., Black, S. E., Jensen, S., \& Lleras-Muney, A. (2019). Breaking the glass ceiling? The effect of board quotas on female labour market outcomes in Norway. The Review of Economic Studies, 86(1), 191-239.

Bishu, S. G., \& Alkadry, M. G. (2017). A systematic review of the gender pay gap and factors that predict it. Administration E Society, 49(1), 65-104.Available at: https://doi.org/10.1177/0095399716636928.

Blau, F. D., \& Kahn, L. M. (2017). The gender wage gap: Extent, trends, and explanations. Journal of Economic Literature, 55(3), 789-865.Available at: https://doi.org/10.1257/jel.20160995.

Chung, M., Ko, E., Joung, H., \& Kim, S. J. (2018). Chatbot e-service and customer satisfaction regarding luxury brands. Journal of Business Research.Available at: https://doi.org/10.1016/j.jbusres.2018.10.004. 
Cox, J. (2019). The glass ceiling to workplace gender equality still looks bulletproof. Retrived from: https://www.independent.co.uk/preview-of-the-year-2019/gender-pay-gap-women-workplace-equality-sharedparental-leave-ftse-100-a8655676.html [Accessed 7 Apr. 2020].

Fortin, N. M., Bell, B., \& Böhm, M. (2017). Top earnings inequality and the gender pay gap: Canada, Sweden, and the United Kingdom. Labour Economics, 47, 107-123.Available at: https://doi.org/10.1016/j.labeco.2017.05.010.

Lips, H. M. (2013). The gender pay gap: Challenging the rationalizations. Perceived equity, discrimination, and the limits of human capital models. Sex Roles, 68(3-4), 169-185.Available at: https://doi.org/10.1007/s11199-012-0165-z.

Lowry, P. B., \& Gaskin, J. (2014). Partial least squares (PLS) structural equation modeling (SEM) for building and testing behavioral causal theory: When to choose it and how to use it. IEEE Transactions on Professional Communication, 57(2), 123-146.Available at: https://doi.org/10.1109/tpc.2014.2312452.

Marsh, H. W., Guo, J., Dicke, T., Parker, P. D., \& Craven, R. G. (2020). Confirmatory factor analysis (CFA), exploratory structural equation modeling (ESEM), and set-ESEM: optimal balance between goodness of fit and parsimony. Multivariate Behavioral Research, 55(1), 102-119.Available at: https://doi.org/10.1080/00273171.2019.1602503.

Nilufer Azeez, P., \& Priyadarshini, R. (2018). Glass ceiling factors affecting women career advancement in IT industry in India. MSEEE, 390(1), 012021 .Available at: https://doi.org/10.1088/1757-899x/390/1/012021.

Oppenheim, M. (2019). More than a quarter of women have never requested a pay rise, study finds. Retrived from: https://www.independent.co.uk/news/uk/home-news/pay-rise-women-work-awkward-gender-pay-gapa9147931.html. [Accessed 7 Apr. 2020].

Oppenheim, M. (2019a). Four in five women 'not negotiating pay when applying for jobs'. Retrieved from: https://www.independent.co.uk/news/uk/home-news/women-gender-pay-gap-wage-salary-income-latesta9304536.html [Accessed 7 Apr. 2020].

Rai, U. K., \& Srivastava, D. (2010). Women executives and the glass ceiling: Myths and mysteries from Razia Sultana to Hillary Clinton. BHU Management Review, 1, 79-83.

Ryan, M., \& Haslam, A. (2011). The glass cliff: Evidence that women are overrepresented in precarious leadership positions. British Journal of Management, 16(2), 81-90.

Savage, M. (2018). Top-paid men outstrip women by 4 to 1 , shock figures reveal. [online] the Guardian. Retrieved from: https://www.theguardian.com/uk-news/2018/mar/10/top-paid-men-women-gender-gap [Accessed 7 Apr. 2020].

Sharma, S., \& Sehrawat, P. (2014). Glass ceiling for women: Does it exist in the modern India. Journal of Organization $\Xi^{\circ}$ Human Behaviour, 3(2-3), 9-15.

Shmueli, G., Sarstedt, M., Hair, J. F., Cheah, J.-H., Ting, H., Vaithilingam, S., \& Ringle, C. M. (2019). Predictive model assessment in PLS-SEM: Guidelines for using PLSpredict. European Journal of Marketing, 53(11), 2322 to 2347.Available at: https://doi.org/10.1108/ejm-02-2019-0189.

Taber, K. S. (2018). The use of Cronbach's alpha when developing and reporting research instruments in science education. Research in Science Education, 48(6), 1273-1296.Available at: https://doi.org/10.1007/s11165-016-9602-2.

Xiu, L., \& Gunderson, M. (2014). Glass ceiling or sticky floor? Quantile regression decomposition of the gender pay gap in China. International Journal of Manpower, 35(3), 306-326.Available at: https://doi.org/10.1 108/ijm-01-2012-0017.

Yehia, A. F., Saleh, M., \& Ahmed, A. (2016). An adjusted correlation coefficient for canonical correlation analysis. J Egypt Stat Soc, 1-5. 